\title{
Radiation therapy in the prevention and management of brain metastases in patients with small cell lung cancer: a narrative review
}

\author{
Eric Hau ${ }^{1,2,3}$, Rebecca Lim $^{4}$, Shalini Vinod ${ }^{5,6}$, Najmun Nahar ${ }^{1}$, Harriet Gee ${ }^{1,7,8}$, Mark B. Pinkham,10 \\ ${ }^{1}$ Sydney West Radiation Oncology Network, Sydney, Australia; ${ }^{2}$ Westmead Clinical School, University of Sydney, Sydney, Australia; ${ }^{3}$ Westmead \\ Institute of Medical Research, Sydney, Australia; ${ }^{4}$ Department of Radiology, Westmead hospital, Sydney, Australia; ${ }^{5}$ Liverpool Cancer Therapy \\ Centre, Liverpool, Australia; ${ }^{6}$ South Western Sydney Clinical School, UNSW \& Ingham Institute for Applied Medical Research, Liverpool, \\ Australia; ${ }^{7}$ Children's Medical Research Institute, Sydney, Australia; ${ }^{8}$ University of Sydney, Sydney, Australia; ${ }^{9}$ Radiation Oncology, Cancer Services, \\ Princess Alexandra Hospital, Brisbane, Australia; ${ }^{10}$ School of Medicine, University of Queensland, Brisbane, Australia \\ Contributions: (I) Conception and design: E Hau; (II) Administrative support: None; (III) Provision of study materials or patients: MB Pinkham; \\ (IV) Collection and assembly of data: All authors; (V) Data analysis and interpretation: All authors; (VI) Manuscript writing: All authors; \\ (VII) Final approval of manuscript: All authors. \\ Correspondence to: Eric Hau. Sydney West Radiation Oncology Network, Sydney, Australia; Westmead Clinical School, University of Sydney, Sydney, \\ Australia; Westmead Institute of Medical Research, Sydney, Australia. Email: eric.hau@health.nsw.gov.au.
}

\begin{abstract}
Objective: The purpose of this narrative review is to survey the current literature and provide treatment recommendations for the management of patients with brain metastases (BMs) from small cell lung cancer (SCLC).

Background: BMs are very common in patients with SCLC and management has changed significantly in recent years. Radiation techniques and systemic therapies have evolved and this review will highlight these recent studies and implications on clinical practice.

Methods: This narrative review covers prophylaxis and treatment of established BMs in patients with SCLC. Studies included are based on Medline, PubMed, Google scholar searches, abstracts from conference proceedings and references from published papers.

Conclusions: Radiation therapy continue to have an important role in the prophylaxis and treatment of patients with BMs. Radiation technologies have resulted in significant reduction of toxicities and improved quality of life (QoL). There continues to be many unanswered questions and results of currently accruing trials will hopefully fill some of these gaps and refine the role of radiation therapy in the management of this condition.
\end{abstract}

Keywords: Small cell lung cancer (SCLC); brain metastases (BMs); whole brain radiation therapy (WBRT); stereotactic radiosurgery; immunotherapy

Submitted Aug 05, 2021. Accepted for publication Oct 09, 2021.

doi: $10.21037 / \mathrm{cco}-21-108$

View this article at: https://dx.doi.org/10.21037/cco-21-108

\section{Introduction}

Small cell lung cancer (SCLC) accounts for $10-15 \%$ of all lung tumours. Although the American Joint Committee on Cancer (AJCC) system (1) can be used, from a practical perspective most patients are staged using the system proposed by the Veterans Administration (VA) health care which classifies SCLC into two stages (1). Limited stage SCLC (LS-SCLC) refers to locoregional disease that can be safely treated within radiotherapy fields and comprises approximately one-third of all SCLC. Extensive stage SCLC (ES-SCLC) encompasses metastatic disease and intrathoracic disease that is too extensive to be amenable to 


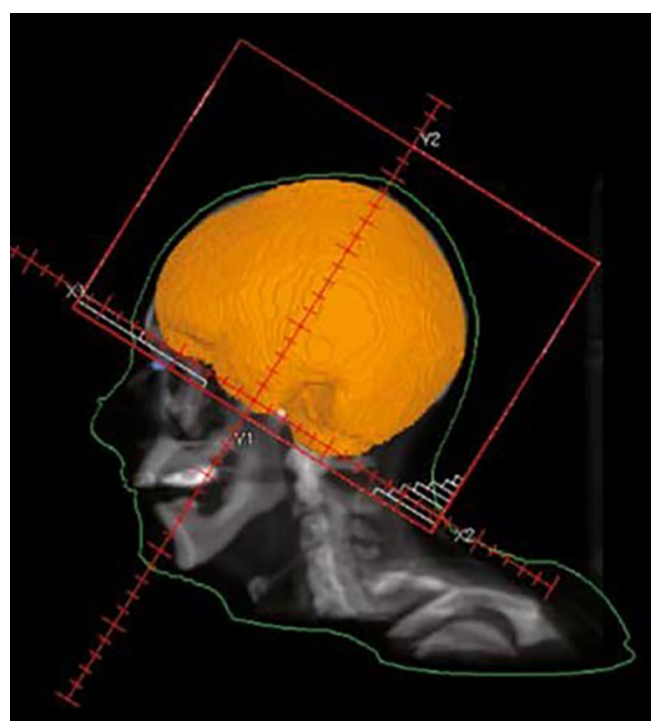

Figure 1 Typical arrangement of opposed lateral fields to treat a patient with WBRT. WBRT, whole brain radiation therapy.

curative-intent radiotherapy and accounts for approximately two-thirds of SCLC (2).

Brain metastases (BMs) are more common in patients with SCLC than many other primary cancer histologies. Approximately $40-60 \%$ of patients with SCLC will develop $\mathrm{BM}$ during the course of their disease (3-5). For decades, whole brain radiation therapy (WBRT) (Figure 1) has played a central function in the prevention and treatment of BM from SCLC. The aim of this paper is to review the historical and evolving roles of radiation therapy in the overall management of patients with SCLC. We present the following article in accordance with the Narrative Review reporting checklist (available at https://cco.amegroups.com/ article/view/10.21037/cco-21-108/rc).

\section{Prophylactic cranial irradiation (PCI) in LS-SCLC}

The Aupérin et al. meta-analysis investigated the role of PCI across seven randomised trials in 987 patients with any stage SCLC and a complete response following chemotherapy. PCI significantly improved the 3 -year overall survival (OS) by $5.4 \%$ and reduced incidence of $\mathrm{BM}$ by a relative risk of 0.46 (95\% CI: 0.38-0.57) (6). A further meta-analysis including both LS-SCLC and ES-SCLC confirmed an improvement in OS with a hazard ratio (HR) of 0.81 (95\% CI: 0.67-0.99). The study also found a reduction in BM with a HR 0.45 (95\% CI: 0.38-0.55) in favour of PCI though there was significant heterogeneity in brain imaging following chemo- radiation (7). Restaging magnetic resonance imaging (MRI) brain following completion of chemo-radiation should be considered given that interval BM occur in $20-32 \%$ of patients $(8,9)$. However, even following a negative restaging brain MRI, BM subsequently occur in $37-41 \%$ of patients without PCI $(10,11)$. The addition of PCI in this population was associated with an improved OS, BM-free survival and time to progression (10,12-16).

Approximately $40-50 \%$ of patients with LS-SCLC patients do not receive PCI in an attempt to avoid potential neuro-cognitive effects associated with cranial irradiation $(13,17)$. It should be noted however that many patients with SCLC have neurological and cognitive deficits prior to the delivery of PCI with rates up to $47 \%$ reported (18-21). Patients with increasing age are considered less likely to benefit from PCI and also at increased risk of neurocognitive detriment $(22,23)$. Many of the randomized trials of PCI did not include patients over 70 years of age and retrospective series report conflicting results. Farooqi et al. performed a retrospective review of 658 patients at MD Anderson and found no OS benefit for patients $\geq 70$ years and primary tumours $\geq 5 \mathrm{~cm}$ (12). However, a population-based analysis using the SEER database suggested an association between superior OS in those over 70 years who received PCI than those who did not. Receipt of PCI remained an independent significant predictor of improved survival even after adjusting for multiple other patient and tumor characteristics (24) but data on neuro-cognitive outcomes was lacking. These studies highlight that advanced age alone may not be a reliable factor for decision-making with regards to PCI, and a more holistic approach may be required to select the most appropriate patients.

Another subgroup that may be less likely to benefit from PCI include the minority of patients that present with stage I disease (25-27). A systemic review and meta-analysis has shown no improvement in OS with HR 0.87 (95\% CI: $0.34-2.24)$ and a relatively low 5 year BM incidence of $12 \%$ (95\% CI: 8-17\%) (28).

PCI for LS-SCLC is usually given after completion of all chemotherapy and thoracic radiotherapy, although in some instances it may be given concurrently with thoracic radiotherapy if this has been delayed until after chemotherapy. The recommended dose is $25 \mathrm{~Gy}$ in 10 fractions. Randomized evidence has shown that higher doses of 36 Gy in 18 fractions or an accelerated regime of 36 Gy in 24 fractions given twice daily were not associated with reduced BM with HR 0.80 (95\% CI: 0.57-1.11) but in fact inferior OS with HR 1.20 (95\% CI: 1.00-1.44) (29) and 
greater chronic neurotoxicity (22).

ASCO, ASTRO and NCCN recommend that PCI should remain standard of care for patients with LS-SCLC and complete or partial response following initial therapy $(30,31)$ though subgroups with lesser benefit include stage I disease and potentially the elderly. Although not specifically tested in the setting of PCI, adding memantine (an NMDA receptor antagonist and putative radioprotectant) may be considered given reduced neuro-cognitive decline with WBRT in the setting of established BM (32). Patient selection remains challenging and geriatric screening to identify patients most at risk of neuro-cognitive decline and involvement of patient preferences are important considerations (33-35). Prognostic tools are also available to assist in decision making and are discussed below.

\section{$\mathrm{PCI}$ in ES-SCLC}

The Aupérin et al. meta-analysis discussed above also demonstrated benefit of PCI in patients with ES-SCLC and a complete response to initial therapy (6). However, complete responses are uncommon in patients with ESSCLC. The EORTC conducted a 286 patient phase 3 randomized trial of PCI in patients with ES-SCLC. PCI was associated with a reduction in symptomatic BM with HR 0.27 (0.16-0.44), reduced cumulative incidence of BM at 1 year $(14.6 \%$ versus $40.4 \%)$ and improvement in 1 year OS (13.3\% versus $27.1 \%$ ) (36). This study however, lacked brain MRI for both staging and follow up and therefore the benefit seen with PCI may have been attributable to the treatment of occult disease.

A Japanese study randomized ES-SCLC patients with a negative brain MRI with any response following chemotherapy to PCI versus observation and relapsedirected therapy. Surveillance imaging involved MRI brain every 3 months for the first year then at 18 and 24 months after enrolment. In this study, although PCI reduced the cumulative incidence of $\mathrm{BM}$ at 18 months $(63.8 \%$ versus $40.1 \%)$, there was no significant difference in OS with HR 1.27 (95\% CI: 0.96-1.68). The study was terminated early following the first interim analysis of 163 patients based on futility. No differences in neuro-cognitive function according to mini-mental state examination (MMSE) scores were found between the study arms, but this is an insensitive tool and further analyses of subgroups were not reported. Of the patients who developed BM in the control arm, $83 \%$ received subsequent radiation therapy (37). There are a number of caveats in this study; Japan has the one of the highest number of MRI per capital in the world, the patient population was likely to be a highly selected group with a high proportion receiving $4^{\text {th }}$ line chemotherapy $(26 \%$ in PCI and $35 \%$ in observation arm) and recruitment rate was slow at roughly 1 patient per centre per year. The apparent lack of survival benefit may be explained by the exclusion of patients with occult BM (which should be present in around $10 \%$ of patients). However, in the EORTC trial, the incidence of $\mathrm{BM}$ was similar to the control group of a study in LS-SCLC with brain imaging (mostly CT) performed for the majority of patients (38). Furthermore, a subgroup analysis excluding patients with symptomatic BM in the first 2 months continued to show a benefit of PCI (39).

The impact of these studies on clinical management has been variable. A recent survey in the US demonstrates a significant reduction in radiation oncologists routinely offering PCI in ES-SCLC from $78 \%$ to $38 \%$ (40). In contrast, a panel of ESTRO and IASLC representing European radiation and medical oncologists specializing in lung cancer continue to recommend PCI for fit, non-elderly patients who respond to chemotherapy. MRI surveillance was not suggested by most experts (41).

Neuro-cognitive decline can occur following cranial irradiation. Hippocampal avoidance WBRT (HA-WBRT) can ameliorate these effects (Figure 2) and combined with memantine, this approach has been shown to be effective in reducing cognitive decline and patient reported symptoms in patients with BM from histologies other than SCLC (42). In the setting of PCI for SCLC, the Spanish PREMER trial using the Free and Cued Selective Reminding Test (FCSRT) showed decreased neuro-cognitive decline in the HAWBRT arm (43) but another phase III randomized trial of 168 patients using total recall on the HVLT-revised score at 4 months did not find any benefit (44). The discrepancies between these results may relate to different endpoints, underpowering of the studies, different hippocampal constraints for HA-WBRT and the absence of radiotherapy and radiology central reviews.

There are now efforts to abandon PCI altogether. Using MRI surveillance with relapse-directed therapy is one approach and there are ongoing trials such as SWOG 1827 (clinicalTrials.gov: NCT04155034) comparing PCI with MRI surveillance in both LS-SCLC and ES-SCLC. However, depending on the local healthcare system, there may be significant patient costs associated with the need to undergo regular follow-up imaging. Other approaches include the use of stereotactic radiosurgery (SRS) (discussed in next section) and shifting paradigms in systemic therapies. 


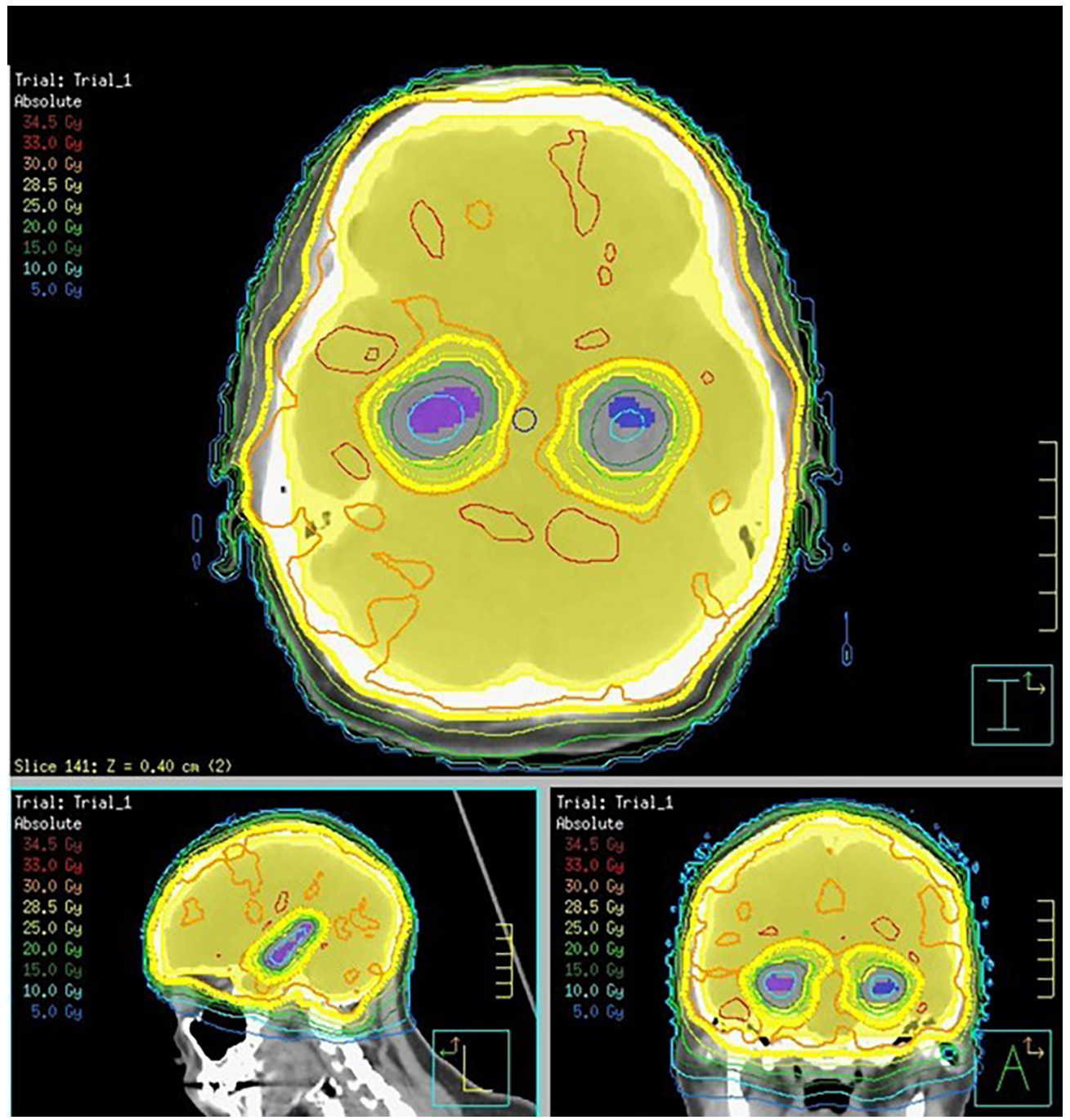

Figure 2 Radiation plan for HA-WBRT. HA-WBRT, hippocampal avoidance whole brain radiation therapy.

Increased utilization of checkpoint inhibitors in ES-SCLC may impact the utility of PCI. The two randomized studies IM-Power 133 (45) and CASPIAN (46) added atezolizumab and durvalumab to standard chemotherapy backbones and showed a modest OS improvement with this approach. The CASPIAN trial allowed PCI in the chemotherapy alone arm but only $8 \%$ (21 patients) received it (47) and although PCI was permitted in both arms of the IM-Power 133 trial, only $11 \%$ (22 patients) in each arm received it (45). The IMPower 133 study showed that atezolizumab significantly delayed the time to intracranial progression (20.2 months versus 10.5 months, $\mathrm{P}=0.046$ ) compared with placebo (48). Similarly, in the setting of AJCC stage III non-small cell lung cancer (NSCLC), the PACIFIC trial showed that the addition of adjuvant durvalumab reduced the incidence of BM from $11.8 \%$ to $6.3 \%$ (49). Thus, the use of immunotherapy may potentially negate the marginal OS benefit of adding PCI and may be important in deciding whether to offer PCI to patients in the future.

ASCO, ASTRO and NCCN currently recommend shared decision making around PCI for patients with ESSCLC $(30,31)$ and we also support this approach given the many nuances surrounding benefit versus risk that must be individualized. Decision aids may be helpful in assisting patients to make an informed decision and are available online https://decisionaid.ohri.ca/ (50). 


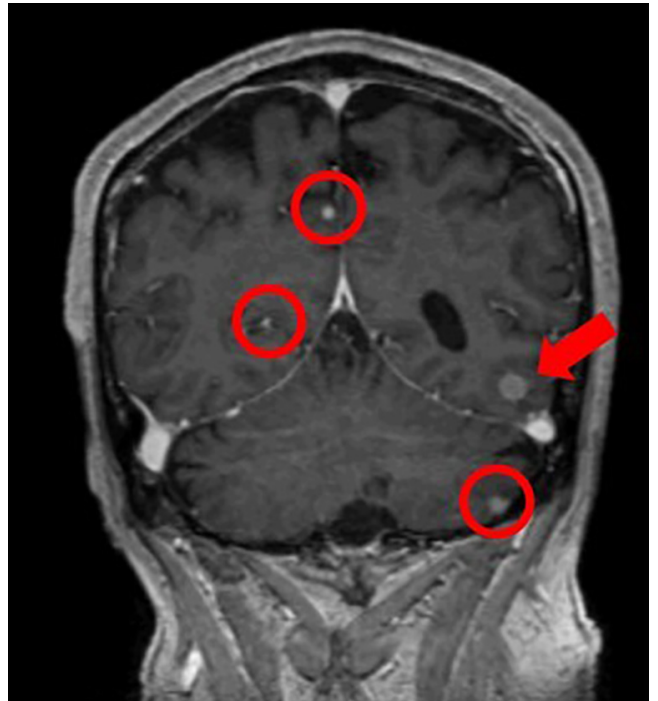

Figure 3 Coronal MRI scan of brain. A CT scan has identified a single lesion (arrow) but MRI scanning has identified further metastases (circles). CT, computed tomography; MRI, magnetic resonance imaging.

\section{Imaging of BM}

Imaging plays a critical role in the screening and detection of SCLC BM and assessment of treatment response. MRI is superior to computed tomography $(\mathrm{CT})$ in the detection of $\mathrm{BM}$, and in refining the differential diagnosis of mass lesions (51-53) (Figure 3). A study comparing the two modalities found that the prevalence of detected $\mathrm{BM}$ in patients with SCLC was $10 \%$ in the CT era and $24 \%$ in the MRI era (53). Furthermore, in the CT era, all detected BM were symptomatic whereas in the MRI era only $11 \%$ were symptomatic (53). The UK National Institute for Health and Care Excellence (NICE) 2021 guidelines recommends MRI with intravenous gadolinium unless contraindicated as the initial diagnostic test for suspected BM (54).

Multiple technical factors in MR acquisition may affect the detection of BM including the dosage of intravenous gadolinium, the timing of scan acquisition post-gadolinium administration, image slice thickness and the magnetic field strength. In a study of 38 patients undergoing T1-weighted MRI prior to SRS, additional BM were seen in $43 \%$ of scans performed 15 minutes compared to 5 minutes after contrast administration (55). Higher magnetic field strengths have been shown to increase lesion conspicuity $(56,57)$. Even with only half the standard intravenous contrast dose, MR imaging at 3.0 $\mathrm{T}$ still yielded higher contrast-to-noise ratio than that with full dose at $1.5 \mathrm{~T}$ (56). The susceptibility weighted sequence (SWI) is frequently used to detect cerebral microhemorrhages which is particularly useful because microscopic bleeding is common in BM and bloodbrain barrier breakdown leading to contrast enhancement is a relatively late stage of BM evolution. A study found that 7.0 T SWI sequence with spatially higher resolution allowed the detection of $20 \%$ more microhemorrhages compared to the $1.5 \mathrm{~T}$ SWI sequence, which may be useful in detecting tiny hemorrhagic metastases that are not apparent on $1.5 \mathrm{~T}$ MR images (58). For SRS planning, careful consideration should also be given to the impact of increasing magnetic field strength on image distortion.

Previously, poor renal function was considered a contraindication to the administration of intravenous gadolinium due to the risk of developing nephrogenic systemic fibrosis (NSF). However, an inaugural consensus statement endorsed by the American College of Radiology and National Kidney Foundation in November 2020 found zero events of NSF following 4,931 administrations of Group II gadolinium-based contrast media (GBCM) to patients with estimated glomerular filtration rate (eGFR) $<30 \mathrm{~mL} / \mathrm{min}$ (59). The consensus statement currently recommends that the potential harm of withholding Group II GBCM for an MRI in a patient with eGFR $<30 \mathrm{~mL} / \mathrm{min}$ is likely to outweigh the risk in most clinical situations. Group II GBCM includes widely-used contrast agents such as MultiHance, ProHance and Gadavist (59).

BM are solitary in up to $45 \%$ of patients (60). MRI plays a pivotal role in differentiating between metastases and similarappearing lesions such as gliomas, lymphoma, demyelinating disorders, cerebral infections and vasculitides (52). In particular, the diffusion weighted imaging (DWI) sequence is often helpful in narrowing the differential diagnosis to glioblastoma and metastases, after which MR spectroscopy (MRS) and MR perfusion imaging can help differentiate these two entities. MRS allows the noninvasive evaluation of the chemical makeup of the brain. Choline is a measure of cellular membrane turnover and is usually increased in disorders that cause increased cellular membrane turnover. Creatinine is a measure of cellular energy and is relatively constant in the brain, therefore it is often used as a reference (61). Elevated peritumoral choline/creatine ratio is often seen with high-grade gliomas, due to peritumoral infiltrating glioma cells (62). This finding is not seen with metastases and can help differentiate between the two $(61,62)$.

Differentiating between post-radiotherapy changes and tumor progression can prove challenging as the effects 


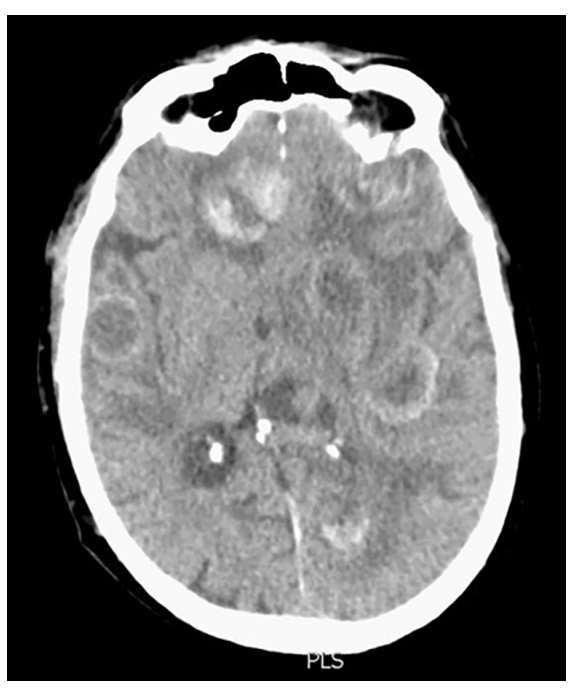

Figure 4 Patient with a high volume of symptomatic BM from SCLC. BM, brain metastases; SCLC, small cell lung cancer.

of radiotherapy can yield similar imaging changes to tumor progression (52). MR perfusion, in particular the relative cerebral blood volume ( $\mathrm{rCBV}$ ) map is helpful in differentiating these two processes. Low $\mathrm{rCBV}$ is seen in regions of post-treatment change, while high $\mathrm{rCBV}$ is seen in tumor recurrence due to increased vascularity (52). Visual inspection of the rCBV level can differentiate tumor recurrence from radiation necrosis following SRS with specificity of $93 \%$ and sensitivity of $70 \%$ which could be increased to $85 \%$ when using a region of interest (ROI) cutoff of 2 (lesion relative to white matter) (63). 6-[(18)F]fluoro-L-3,4-dihydroxyphenylalanine (F-DOPA) positron emission tomograph (PET)-CT also appears promising in differentiating radiation necrosis from tumor progression, and may be superior to perfusion MRI with one study reporting a sensitivity of $90 \%$ and specificity of $92 \%$ (64).

\section{Treatment of BMs}

The optimal management of patients with confirmed BM has also undergone significant changes in recent years. Treatment options include systemic therapy, WBRT with or without hippocampal avoidance (HA-WBRT) and SRS. In general, neurosurgery is not pursued in the management of SCLC BM but may be considered when histological diagnosis or rapid relief of pressure-related symptoms are required in select cases.

WBRT involves treating the entire brain to the same dose which is typically 30 Gy in 10 fractions or 20 Gy in 5 fractions (65). WBRT achieves symptomatic relief with a $50 \%$ response rate (66) and may result in stabilization or improvement in neurological function (67).

In the setting of NSCLC, the Quartz trial did not demonstrate any difference in quality of life (QoL), OS or steroid use between WBRT and best supportive care in patients with BM deemed not suitable for SRS (68). However, many patients in this study had uncontrolled and/or untreated extracranial disease (63\%), the QoL tools used were not specific to neurologic disease and the rates of neurological death were not reported. For SCLC, retrospective studies have shown a small improvement in OS in elderly patients treated with WBRT who did not receive chemotherapy (69).

A recent survey of European radiation and medical oncologists found the main factors considered when deciding on treatment revolve around whether the BM are symptomatic and whether they are limited or not (70). For asymptomatic BM, chemotherapy alone was most commonly recommended while in patients with symptomatic disease, WBRT followed by chemotherapy was favoured (Figure 4). For patients with a limited volume of BM, some experts would use SRS. To best select appropriate patients for SRS, we would consider BM velocity (growth rate of known BM and occurrence of new BM between scans) and the competing risk of extra-cranial disease to be important factors (71).

SRS involves the precise delivery of a high dose of radiotherapy to the tumour alone in 1-5 fractions, whilst minimising dose to the surrounding normal tissues (72) (Figures 5,6). SRS is a standard of care for treatment of $\mathrm{BM}$ when limited in number. From mixed histology BM trials excluding SCLC, SRS has been shown to prolong OS compared to WBRT alone for patients with a single BM and functional independence in those with up to $3 \mathrm{BM}$ (73). As WBRT and SRS utilization has evolved over time, randomised studies have shown that withholding WBRT after definitive local therapy (SRS or neurosurgery) for BM does not compromise OS but is associated with an increased risk of new BM elsewhere in the brain. However, deficits in QoL and neuro-cognitive function associated with the emergence of new BM are less than the deficits associated with upfront WBRT in all patients (74-79). However, patients with SCLC have been largely excluded from these trials due to a perceived shorter interval to intracranial progression, the diffuse and multiplicity of lesions, past success with PCI in reducing the cumulative incidence of $\mathrm{BM}$ and the overall poor prognosis of such patients as a competing risk for OS and neuro-cognitive decline. 

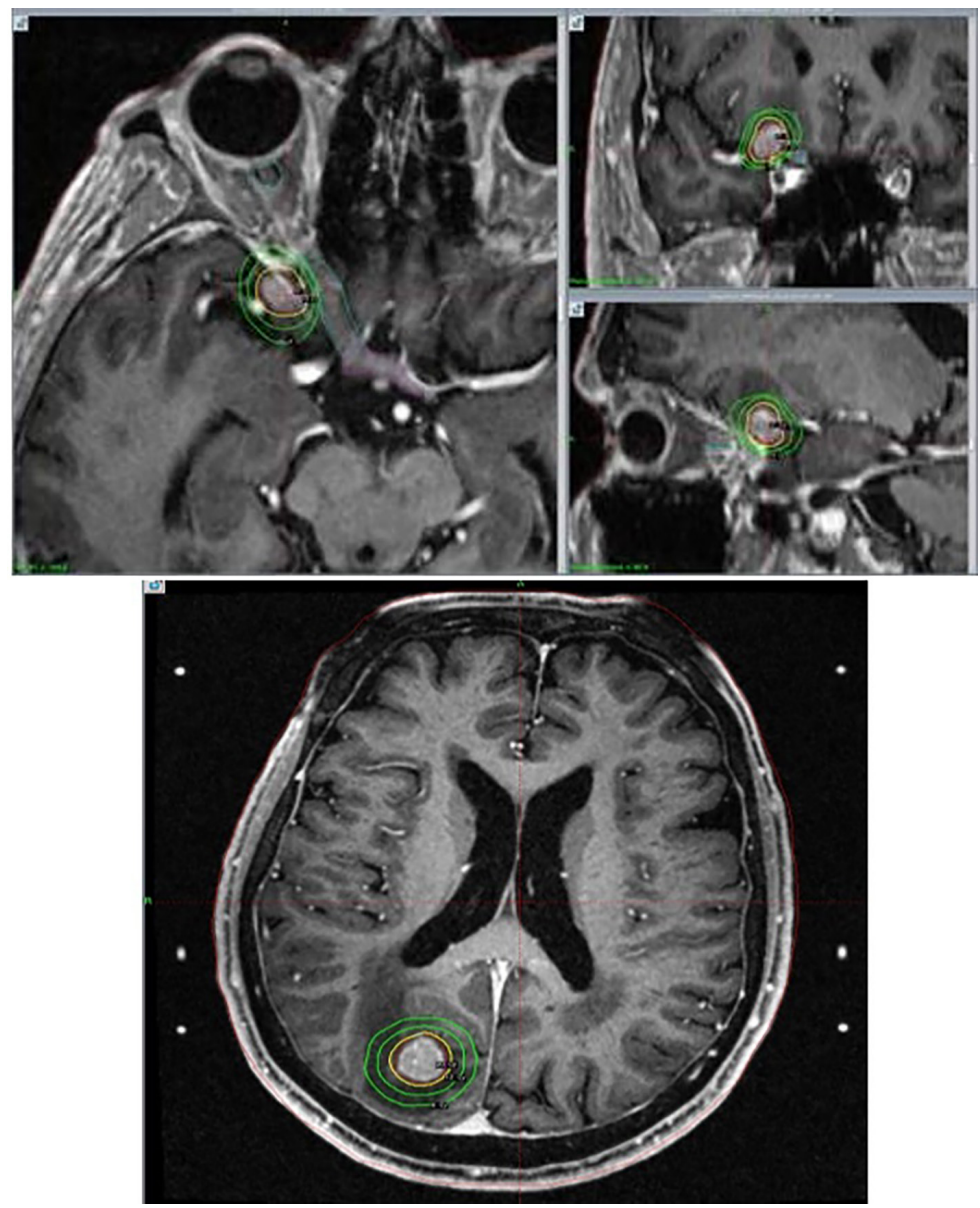

Figure 5 Steep dose gradient achieved using gamma knife SRS for treatment of BM. Yellow isodose 20 Gy, inner green 12 Gy and outer 8 Gy. Right optic nerve <8 Gy max. SRS, stereotactic radiosurgery; BM, brain metastases.

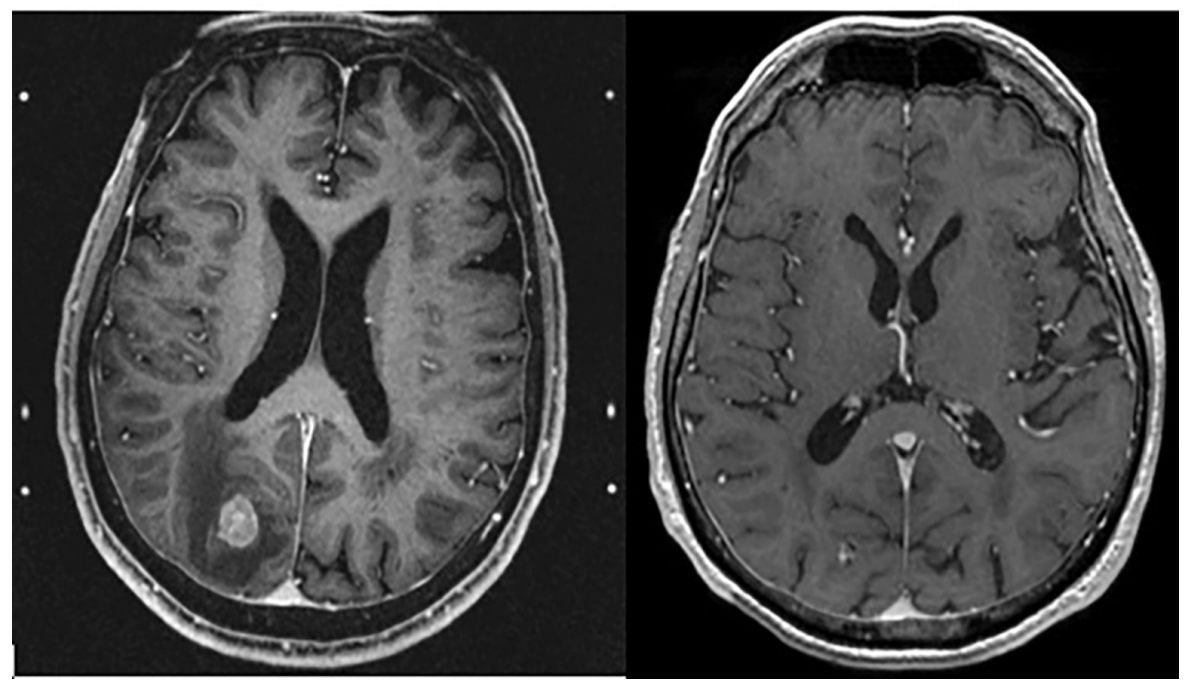

Figure 6 Right occipital BM before and 3 months after SRS. SRS, stereotactic radiosurgery; BM, brain metastases. 
There is however, increasing interest in SRS as first line treatment of BM from SCLC due to the increasing use of MRI screening and improvements in prognosis due to systemic therapies that prolong the 'at risk' period for BM to develop and for patients to experience potential therapyrelated toxicity thereafter. There have been a number of retrospective series reported on the use of SRS for SCLC (80-90). In the largest series, the FIRE-SCLC (First-line Radiosurgery for Small-Cell Lung Cancer) cohort study of 710 patients with $\mathrm{BM}$ who never received PCI across 6 countries demonstrated median OS and time to CNS progression after SRS was 8.5 and 8.1 months, respectively. The rate of brain specific mortality was $12 \%$ and more patients received salvage SRS than WBRT upon further recurrence (34\% versus $16 \%)$. On propensity matching with a WBRT cohort, time to intracranial progression was shorter after SRS than WBRT with HR 0.38 (95\% CI: $0.26-0.55)$ but was not associated with a difference in OS (6.2 months for SRS and 5.2 months for WBRT) (91). Of note 98 patients in this series also participated in the JLGK0901 prospective single-arm trial of SRS for 1 to 10 BMs from mixed histologies (92). Recently, a systematic review and meta-analysis of 9 observational studies using SRS for SCLC found a median survival 8.3 months (95\% CI: 7.1-9.5), BM local control at 12 months $93 \%$ (95\% CI: 91-94\%) and distant brain failure 41\% (33-48\%) (93).

Given there are at least a select group of patients with BM from SCLC with median OS 17 months in the preimmunotherapy era (94) and median OS 12-13 months in the setting of ES-SCLC treated with checkpoint inhibitors and chemotherapy $(45,47)$, the role of SRS may be expanding in this population. There are a number of clinical trials focused on evaluating SRS for patients with SCLC. ENCEPHALON (ClinicalTrials.gov identifier: NCT03297788) is a randomized phase II study of WBRT versus SRS for up to $10 \mathrm{BM}$ aiming to recruit 56 patients with the primary endpoint of neurocognition at 3 months. A single arm Phase II study at Dana-Farber Institute will treat patients with up to $10 \mathrm{BM}$ with SRS with death due to neurological disease as the primary endpoint (ClinicalTrials. gov identifier: NCT03391362) while the NRG-CC09 is a randomized phase III study activated in February 2021 and will compare SRS with HA-WBRT with memantine.

The optimal dose-fractionation for SRS has also not been well established and the meta-analysis mentioned above included studies treated to a median dose of $18 \mathrm{~Gy}$ (17-21 Gy) (93). The ENCEPHALON trial uses 20 Gy in a single fraction for $\mathrm{BM}<2 \mathrm{~cm}$ diameter, $18 \mathrm{~Gy}$ for $\mathrm{BM}$
2-3 cm and 30 Gy in 6 fractions for BM larger than $3 \mathrm{~cm}$. In patients who have received prior PCI or WBRT, small retrospective studies have investigated salvage treatment with SRS reporting local control at 1 year of $57 \%$ but a high rate of distant brain failure $58-61 \%(82,95)$.

For most patients with multiple BM from SCLC, WBRT with either 30 Gy in 10 fractions or 20 Gy in 5 fractions is appropriate. The addition of memantine may result in reduced cognitive decline over time (32). In patients with a more favourable survival, HA-WBRT with memantine may be considered (42). In patients with a smaller number and volume of BM and increased risk of neurocognitive deficits, an SRS approach may be considered acknowledging the need for ongoing surveillance and salvage treatments.

\section{Prognostic tools}

Given the discussions above, it is evident that precise prognostication can inform therapeutic decision making. The diagnosis-specific Graded Prognostic Assessment scores were developed using a database of 3,940 patients with BM. For lung cancer, the prognostic factors include Karnofsky performance score, age, presence of extracranial metastases, and number of BM (94). Using this tool, categories of prognosis ranging from a median survival of 2.79 months in the poorest prognosis group to 17.05 months in the most favourable group may be separated. This tool has been validated in the real-life setting (96). More recently, the labBM score incorporating blood parameters including hemoglobin, white blood cell count, platelet count, serum albumin, creatinine, lactate dehydrogenase (LDH), and C-reactive protein (CRP) has been found to be independently associated with OS in patients with BM (97). These tools may assist in shared decision making and guiding treatment recommendations, balancing OS with an individual's risk for neurological deficits related to uncontrolled metastatic disease and treatments delivered to prevent it.

\section{Conclusions and future direction}

For decades, radiation therapy has had a crucial role in the prevention and treatment of BM in patients with SCLC. However due to the recognition of the potential detrimental effects of WBRT coupled with changing systemic therapies and increasing utilization of SRS for BM from other histologies, the role of radiation in SCLC is also evolving.

There are several studies such as the ENCEPHALON and the NRG-CC09 which will be important in refining 
how radiation therapy should be best utilized. Ongoing studies will also better define the population who benefit most from PCI and those who can be safely monitored with MRI surveillance and salvage-directed therapy. As systemic therapies change, patterns of relapse will also likely alter the selection of patients and the way radiation therapy will be delivered. Decision support tools with incorporation of patient preferences are important in tailoring radiotherapy for individual patients with SCLC.

\section{Acknowledgments}

Funding: None.

\section{Footnote}

Provenance and Peer Review: This article was commissioned by the Guest Editors (Simon S. Lo, Balamurugan Vellayappan, Kevin Shiue and Jonathan P. S. Knisely) for the series "The Modern Approaches to the Management of Brain Metastases" published in Chinese Clinical Oncology. The article has undergone external peer review.

Reporting Checklist: The authors have completed the Narrative Review reporting checklist. Available at https:// cco.amegroups.com/article/view/10.21037/cco-21-108/rc

Conflicts of Interest: All authors have completed the ICMJE uniform disclosure form (available at https://cco. amegroups.com/article/view/10.21037/cco-21-108/coif). The series "The Modern Approaches to the Management of Brain Metastases" was commissioned by the editorial office without any funding or sponsorship. SV reports payment or honoraria for lectures, presentations, speakers bureaus, manuscript writing or educational events from Astra Zeneca. MBP reports honoraria/speaker fees from Roche, BMS, AZ; and shareholder of ICON Cancer Care, Australia. EH reports honoraria and research grant funding from Astra Zeneca. The authors have no other conflicts of interest to declare.

Ethical Statement: The authors are accountable for all aspects of the work in ensuring that questions related to the accuracy or integrity of any part of the work are appropriately investigated and resolved.

Open Access Statement: This is an Open Access article distributed in accordance with the Creative Commons
Attribution-NonCommercial-NoDerivs 4.0 International License (CC BY-NC-ND 4.0), which permits the noncommercial replication and distribution of the article with the strict proviso that no changes or edits are made and the original work is properly cited (including links to both the formal publication through the relevant DOI and the license). See: https://creativecommons.org/ licenses/by-nc-nd/4.0/.

\section{References}

1. Lababede O, Meziane MA. The Eighth Edition of TNM Staging of Lung Cancer: Reference Chart and Diagrams. Oncologist 2018;23:844-8.

2. Micke P, Faldum A, Metz T, et al. Staging small cell lung cancer: Veterans Administration Lung Study Group versus International Association for the Study of Lung Cancer-what limits limited disease? Lung Cancer 2002;37:271-6.

3. Lukas RV, Gondi V, Kamson DO, et al. State-of-the-art considerations in small cell lung cancer brain metastases. Oncotarget 2017;8:71223-33.

4. Hirsch FR, Paulson OB, Hansen HH, et al. Intracranial metastases in small cell carcinoma of the lung. Prognostic aspects. Cancer 1983;51:529-33.

5. Nugent JL, Bunn PA Jr, Matthews MJ, et al. CNS metastases in small cell bronchogenic carcinoma: increasing frequency and changing pattern with lengthening survival. Cancer 1979;44:1885-93.

6. Aupérin A, Arriagada R, Pignon JP, et al. Prophylactic cranial irradiation for patients with small-cell lung cancer in complete remission. Prophylactic Cranial Irradiation Overview Collaborative Group. N Engl J Med 1999;341:476-84.

7. Yin X, Yan D, Qiu M, et al. Prophylactic cranial irradiation in small cell lung cancer: a systematic review and metaanalysis. BMC Cancer 2019;19:95.

8. Manapov F, Klautke G, Fietkau R. Prevalence of brain metastases immediately before prophylactic cranial irradiation in limited disease small cell lung cancer patients with complete remission to chemoradiotherapy: a single institution experience. J Thorac Oncol 2008;3:652-5.

9. Yılmaz U, Kurakli EK, Gürlek Ü, et al. Frequency of Silent Brain Metastasis Before Prophylactic Cranial Irradiation in Small Cell Lung Cancer. Turk Thorac J 2017;18:11-3.

10. Eze C, Roengvoraphoj O, Niyazi M, et al. Treatment Response and Prophylactic Cranial Irradiation Are Prognostic Factors in a Real-life Limited-disease Smallcell Lung Cancer Patient Cohort Comprehensively Staged 
With Cranial Magnetic Resonance Imaging. Clin Lung Cancer 2017;18:e243-9.

11. Zheng $\mathrm{Y}$, Wang $\mathrm{L}$, Zhao $\mathrm{W}$, et al. Risk factors for brain metastasis in patients with small cell lung cancer without prophylactic cranial irradiation. Strahlenther Onkol 2018;194:1152-62.

12. Farooqi AS, Holliday EB, Allen PK, et al. Prophylactic cranial irradiation after definitive chemoradiotherapy for limited-stage small cell lung cancer: Do all patients benefit? Radiother Oncol 2017;122:307-12.

13. Giuliani M, Sun A, Bezjak A, et al. Utilization of prophylactic cranial irradiation in patients with limited stage small cell lung carcinoma. Cancer 2010;116:5694-9.

14. Qiu G, DU X, Zhou X, et al. Prophylactic cranial irradiation in 399 patients with limited-stage small cell lung cancer. Oncol Lett 2016;11:2654-60.

15. Li J, Ding C, Yang C, et al. Prophylactic cranial irradiation confers favourable prognosis for patients with limitedstage small cell lung cancer in the era of MRI: A propensity score-matched analysis. J Med Imaging Radiat Oncol 2021;65:778-85.

16. Ghanta S, Keller A, Rodríguez-López JL, et al. Utility of Prophylactic Cranial Irradiation for Limited Stage Small Cell Lung Cancer in the Modern Era with Magnetic Resonance Imaging Surveillance. Clin Oncol (R Coll Radiol) 2021;33:e323-30.

17. Lok BH, Ma J, Foster A, et al. Factors influencing the utilization of prophylactic cranial irradiation in patients with limited-stage small cell lung cancer. Adv Radiat Oncol 2017;2:548-54.

18. van Oosterhout AG, Boon PJ, Houx PJ, et al. Follow-up of cognitive functioning in patients with small cell lung cancer. Int J Radiat Oncol Biol Phys 1995;31:911-4.

19. Ahles TA, Silberfarb PM, Herndon J 2nd, et al. Psychologic and neuropsychologic functioning of patients with limited small-cell lung cancer treated with chemotherapy and radiation therapy with or without warfarin: a study by the Cancer and Leukemia Group B. J Clin Oncol 1998;16:1954-60.

20. Gregor A, Cull A, Stephens RJ, et al. Prophylactic cranial irradiation is indicated following complete response to induction therapy in small cell lung cancer: results of a multicentre randomised trial. United Kingdom Coordinating Committee for Cancer Research (UKCCCR) and the European Organization for Research and Treatment of Cancer (EORTC) Eur J Cancer 1997;33:1752-8.

21. Grosshans DR, Meyers CA, Allen PK, et al.
Neurocognitive function in patients with small cell lung cancer : effect of prophylactic cranial irradiation. Cancer 2008;112:589-95.

22. Wolfson AH, Bae K, Komaki R, et al. Primary analysis of a phase II randomized trial Radiation Therapy Oncology Group (RTOG) 0212: impact of different total doses and schedules of prophylactic cranial irradiation on chronic neurotoxicity and quality of life for patients with limiteddisease small-cell lung cancer. Int J Radiat Oncol Biol Phys 2011;81:77-84.

23. Le Péchoux C, Laplanche A, Faivre-Finn C, et al. Clinical neurological outcome and quality of life among patients with limited small-cell cancer treated with two different doses of prophylactic cranial irradiation in the intergroup phase III trial (PCI99-01, EORTC 22003-08004, RTOG 0212 and IFCT 99-01). Ann Oncol 2011;22:1154-63.

24. Eaton BR, Kim S, Marcus DM, et al. Effect of prophylactic cranial irradiation on survival in elderly patients with limited-stage small cell lung cancer. Cancer 2013;119:3753-60.

25. Xu J, Yang H, Fu X, et al. Prophylactic Cranial Irradiation for Patients with Surgically Resected Small Cell Lung Cancer. J Thorac Oncol 2017;12:347-53.

26. Zhu H, Guo H, Shi F, et al. Prophylactic cranial irradiation improved the overall survival of patients with surgically resected small cell lung cancer, but not for stage I disease. Lung Cancer 2014;86:334-8.

27. Wu AJ, Gillis A, Foster A, et al. Patterns of failure in limited-stage small cell lung cancer: Implications of TNM stage for prophylactic cranial irradiation. Radiother Oncol 2017;125:130-5.

28. Yang Y, Zhang D, Zhou X, et al. Prophylactic cranial irradiation in resected small cell lung cancer: A systematic review with meta-analysis. J Cancer 2018;9:433-9.

29. Le Péchoux C, Dunant A, Senan S, et al. Standard-dose versus higher-dose prophylactic cranial irradiation (PCI) in patients with limited-stage small-cell lung cancer in complete remission after chemotherapy and thoracic radiotherapy (PCI 99-01, EORTC 22003-08004, RTOG 0212, and IFCT 99-01): a randomised clinical trial. Lancet Oncol 2009;10:467-74.

30. Daly ME, Ismaila N, Decker RH, et al. Radiation Therapy for Small-Cell Lung Cancer: ASCO Guideline Endorsement of an ASTRO Guideline. J Clin Oncol 2021;39:931-9.

31. Simone CB 2nd, Bogart JA, Cabrera AR, et al. Radiation Therapy for Small Cell Lung Cancer: An ASTRO Clinical Practice Guideline. Pract Radiat Oncol 2020;10:158-73. 
32. Brown PD, Pugh S, Laack NN, et al. Memantine for the prevention of cognitive dysfunction in patients receiving whole-brain radiotherapy: a randomized, double-blind, placebo-controlled trial. Neuro Oncol 2013;15:1429-37.

33. Lehman M, Gorayski P, Watson S, et al. Patient preferences regarding prophylactic cranial irradiation: A discrete choice experiment. Radiother Oncol 2016;121:225-31.

34. Lester-Coll NH, Dosoretz AP, Hayman JA, et al. Health State Utilities for Patients with Brain Metastases. Cureus 2016;8:e667.

35. Extermann M, Hurria A. Comprehensive geriatric assessment for older patients with cancer. J Clin Oncol 2007;25:1824-31.

36. Slotman B, Faivre-Finn C, Kramer G, et al. Prophylactic cranial irradiation in extensive small-cell lung cancer. $\mathrm{N}$ Engl J Med 2007;357:664-72.

37. Takahashi T, Yamanaka T, Seto T, et al. Prophylactic cranial irradiation versus observation in patients with extensive-disease small-cell lung cancer: a multicentre, randomised, open-label, phase 3 trial. Lancet Oncol 2017;18:663-71.

38. Arriagada R, Le Chevalier T, Borie F, et al. Prophylactic cranial irradiation for patients with small-cell lung cancer in complete remission. J Natl Cancer Inst 1995;87:183-90.

39. Slotman BJ. Time to reconsider prophylactic cranial irradiation in extensive-stage small-cell lung cancer? Lancet Oncol 2017;18:566-7.

40. Gjyshi O, Ludmir EB, Dursteler A, et al. The Impact of the Stage III Randomized Trial by Takahashi et al. on the Use of Prophylactic Cranial Irradiation (PCI) in Patients with Extensive-Stage Small-Cell Lung Cancer (ES-SCLC). Int J Radiat Oncol Biol Phys 2019;104:230.

41. Putora PM, Glatzer M, Belderbos J, et al. Prophylactic cranial irradiation in stage IV small cell lung cancer: Selection of patients amongst European IASLC and ESTRO experts. Radiother Oncol 2019;133:163-6.

42. Brown PD, Gondi V, Pugh S, et al. Hippocampal Avoidance During Whole-Brain Radiotherapy Plus Memantine for Patients With Brain Metastases: Phase III Trial NRG Oncology CC001. J Clin Oncol 2020;38:1019-29.

43. De Dios NR, Murcia M, Counago F, et al. Phase III Trial of Prophylactic Cranial Irradiation with or without Hippocampal Avoidance for SMALL-CELL LUNG Cancer. Int J Radiat Oncol Biol Phys 2019;105:S35-6.

44. Belderbos JSA, De Ruysscher DKM, De Jaeger K, et al. Phase 3 Randomized Trial of Prophylactic Cranial
Irradiation With or Without Hippocampus Avoidance in SCLC (NCT01780675). J Thorac Oncol 2021;16:840-9.

45. Horn L, Mansfield AS, Szczęsna A, et al. First-Line Atezolizumab plus Chemotherapy in Extensive-Stage Small-Cell Lung Cancer. N Engl J Med 2018;379:2220-9.

46. Goldman JW, Dvorkin M, Chen Y, et al. Durvalumab, with or without tremelimumab, plus platinum-etoposide versus platinum-etoposide alone in first-line treatment of extensive-stage small-cell lung cancer (CASPIAN): updated results from a randomised, controlled, open-label, phase 3 trial. Lancet Oncol 2021;22:51-65.

47. Paz-Ares L, Dvorkin M, Chen Y, et al. Durvalumab plus platinum-etoposide versus platinum-etoposide in firstline treatment of extensive-stage small-cell lung cancer (CASPIAN): a randomised, controlled, open-label, phase 3 trial. Lancet 2019;394:1929-39.

48. Higgins KA, Curran WJ Jr, Liu SV, et al. Patterns of Disease Progression after Carboplatin/Etoposide + Atezolizumab in Extensive-Stage Small-Cell Lung Cancer (ES-SCLC). Int J Radiat Oncol Biol Phys 2020;108:1398.

49. Antonia SJ, Villegas A, Daniel D, et al. Overall Survival with Durvalumab after Chemoradiotherapy in Stage III NSCLC. N Engl J Med 2018;379:2342-50.

50. Robin TP, Sannes TS, Spring Kong FM, et al. Physician Bias in Prophylactic Cranial Irradiation Decision MakingAn Opportunity for a Patient Decision Aid. Clin Lung Cancer 2018;19:476-83.

51. Yokoi K, Kamiya N, Matsuguma H, et al. Detection of brain metastasis in potentially operable non-small cell lung cancer: a comparison of CT and MRI. Chest 1999;115:714-9.

52. Pope WB. Brain metastases: neuroimaging. Handb Clin Neurol 2018;149:89-112.

53. Seute T, Leffers P, ten Velde GP, et al. Detection of brain metastases from small cell lung cancer: consequences of changing imaging techniques (CT versus MRI). Cancer 2008;112:1827-34.

54. National Institute for Health and Care Excellence: Clinical Guidelines. Brain tumours (primary) and brain metastases in adults. London: National Institute for Health and Care Excellence (UK), 2021.

55. Kushnirsky M, Nguyen V, Katz JS, et al. Time-delayed contrast-enhanced MRI improves detection of brain metastases and apparent treatment volumes. J Neurosurg 2016;124:489-95.

56. Krautmacher C, Willinek WA, Tschampa HJ, et al. Brain tumors: full- and half-dose contrast-enhanced MR imaging at 3.0 $\mathrm{T}$ compared with 1.5 T--Initial Experience. 
Radiology 2005;237:1014-9.

57. Noebauer-Huhmann IM, Szomolanyi P, Kronnerwetter C, et al. Brain tumours at 7T MRI compared to 3T--contrast effect after half and full standard contrast agent dose: initial results. Eur Radiol 2015;25:106-12.

58. Mönninghoff C, Maderwald S, Theysohn JM, et al. Imaging of brain metastases of bronchial carcinomas with 7 T MRI - initial results. Rofo 2010;182:764-72.

59. Weinreb JC, Rodby RA, Yee J, et al. Use of Intravenous Gadolinium-based Contrast Media in Patients with Kidney Disease: Consensus Statements from the American College of Radiology and the National Kidney Foundation. Radiology 2021;298:28-35.

60. Schwartz KM, Erickson BJ, Lucchinetti C. Pattern of $\mathrm{T} 2$ hypointensity associated with ring-enhancing brain lesions can help to differentiate pathology. Neuroradiology 2006; 48:143-9.

61. Lignelli A, Khandji AG. Review of imaging techniques in the diagnosis and management of brain metastases. Neurosurg Clin N Am 2011;22:15-25, v.

62. Law M, Cha S, Knopp EA, et al. High-grade gliomas and solitary metastases: differentiation by using perfusion and proton spectroscopic MR imaging. Radiology 2002;222:715-21.

63. Hoefnagels FW, Lagerwaard FJ, Sanchez E, et al. Radiological progression of cerebral metastases after radiosurgery: assessment of perfusion MRI for differentiating between necrosis and recurrence. J Neurol 2009;256:878-87.

64. Cicone F, Minniti G, Romano A, et al. Accuracy of F-DOPA PET and perfusion-MRI for differentiating radionecrotic from progressive brain metastases after radiosurgery. Eur J Nucl Med Mol Imaging 2015;42:103-11.

65. Tsao MN, Xu W, Wong RK, et al. Whole brain radiotherapy for the treatment of newly diagnosed multiple brain metastases. Cochrane Database Syst Rev 2018;1:CD003869.

66. Chen LK, Huang H, Liao H, et al. Chemotherapy with concurrent brain and thoracic radiotherapy in brain-only metastases of treatment naive small-cell lung cancer: a phase II study. Med Oncol 2012;29:1687-92.

67. Postmus PE, Haaxma-Reiche H, Gregor A, et al. Brainonly metastases of small cell lung cancer; efficacy of whole brain radiotherapy. An EORTC phase II study. Radiother Oncol 1998;46:29-32.

68. Mulvenna P, Nankivell M, Barton R, et al. Dexamethasone and supportive care with or without whole brain radiotherapy in treating patients with nonsmall cell lung cancer with brain metastases unsuitable for resection or stereotactic radiotherapy (QUARTZ): results from a phase 3 , non-inferiority, randomised trial. Lancet 2016;388:2004-14.

69. Renz P, Hasan S, Wegner RE. Survival outcomes after whole brain radiotherapy for brain metastases in older adults with newly diagnosed metastatic small cell carcinoma: A national cancer database (NCDB) analysis. J Geriatr Oncol 2019;10:560-6.

70. Putora PM, Fischer GF, Früh M, et al. Treatment of brain metastases in small cell lung cancer: Decision-making amongst a multidisciplinary panel of European experts. Radiother Oncol 2020;149:84-8.

71. Nicholls LW, Pinkham MB, Bernard A, et al. Radiological Kinetics of Brain Metastases and Clinical Implications for Patients Treated With Stereotactic Radiosurgery. Clin Oncol (R Coll Radiol) 2019;31:34-40.

72. Pinkham MB, Whitfield GA, Brada M. New developments in intracranial stereotactic radiotherapy for metastases. Clin Oncol (R Coll Radiol) 2015;27:316-23.

73. Andrews DW, Scott CB, Sperduto PW, et al. Whole brain radiation therapy with or without stereotactic radiosurgery boost for patients with one to three brain metastases: phase III results of the RTOG 9508 randomised trial. Lancet 2004;363:1665-72.

74. Brown PD, Ballman KV, Cerhan JH, et al. Postoperative stereotactic radiosurgery compared with whole brain radiotherapy for resected metastatic brain disease (NCCTG N107C/CEC.3): a multicentre, randomised, controlled, phase 3 trial. Lancet Oncol 2017;18:1049-60.

75. Aoyama H, Shirato H, Tago M, et al. Stereotactic radiosurgery plus whole-brain radiation therapy vs stereotactic radiosurgery alone for treatment of brain metastases: a randomized controlled trial. JAMA 2006;295:2483-91.

76. Brown PD, Jaeckle K, Ballman KV, et al. Effect of Radiosurgery Alone vs Radiosurgery With Whole Brain Radiation Therapy on Cognitive Function in Patients With 1 to 3 Brain Metastases: A Randomized Clinical Trial. JAMA 2016;316:401-9.

77. Chang EL, Wefel JS, Hess KR, et al. Neurocognition in patients with brain metastases treated with radiosurgery or radiosurgery plus whole-brain irradiation: a randomised controlled trial. Lancet Oncol 2009;10:1037-44.

78. Kocher M, Soffietti R, Abacioglu U, et al. Adjuvant wholebrain radiotherapy versus observation after radiosurgery or surgical resection of one to three cerebral metastases: 
results of the EORTC 22952-26001 study. J Clin Oncol 2011;29:134-41.

79. Soffietti R, Kocher M, Abacioglu UM, et al. A European Organisation for Research and Treatment of Cancer phase III trial of adjuvant whole-brain radiotherapy versus observation in patients with one to three brain metastases from solid tumors after surgical resection or radiosurgery: quality-of-life results. J Clin Oncol 2013;31:65-72.

80. Serizawa T, Ono J, Iichi T, et al. Gamma knife radiosurgery for metastatic brain tumors from lung cancer: a comparison between small cell and non-small cell carcinoma. J Neurosurg 2002;97:484-8.

81. Jo KW, Kong DS, Lim DH, et al. The role of radiosurgery in patients with brain metastasis from small cell lung carcinoma. J Korean Neurosurg Soc 2011;50:99-102.

82. Wegner RE, Olson AC, Kondziolka D, et al. Stereotactic radiosurgery for patients with brain metastases from small cell lung cancer. Int J Radiat Oncol Biol Phys 2011;81:e21-7.

83. Yomo S, Hayashi M. Upfront stereotactic radiosurgery in patients with brain metastases from small cell lung cancer: retrospective analysis of 41 patients. Radiat Oncol 2014;9:152.

84. Robin TP, Jones BL, Amini A, et al. Radiosurgery alone is associated with favorable outcomes for brain metastases from small-cell lung cancer. Lung Cancer 2018;120:88-90.

85. Faramand A, Niranjan A, Kano H, et al. Primary or salvage stereotactic radiosurgery for brain metastatic small cell lung cancer. J Neurooncol. 2019;144:217-25.

86. Cordeiro D, Xu Z, Shepard M, et al. Gamma Knife radiosurgery for brain metastases from small-cell lung cancer: Institutional experience over more than a decade and review of the literature. J Radiosurg SBRT 2019;6:35-43.

87. Cifarelli CP, Vargo JA, Fang W, et al. Role of Gamma Knife Radiosurgery in Small Cell Lung Cancer: A MultiInstitutional Retrospective Study of the International Radiosurgery Research Foundation (IRRF). Neurosurgery 2020;87:664-71.

88. Jiang $W$, Haque $W$, Verma V, et al. Stereotactic radiosurgery for brain metastases from newly diagnosed

Cite this article as: Hau E, Lim R, Vinod S, Nahar N, Gee $\mathrm{H}$, Pinkham MB. Radiation therapy in the prevention and management of brain metastases in patients with small cell lung cancer: a narrative review. Chin Clin Oncol 2022;11(2):12. doi: 10.21037/cco-21-108 small cell lung cancer: practice patterns and outcomes. Acta Oncol 2019;58:491-8.

89. Ni M, Jiang A, Liu W, et al. Whole brain radiation therapy plus focal boost may be a suitable strategy for brain metastases in SCLC patients: a multi-center study. Radiat Oncol 2020;15:70.

90. Dudnik E, Allen AM, Michaeli N, et al. Stereotactic Radiosurgery for Brain Metastases in Small Cell Lung Cancer: The Davidoff Cancer Center Experience. Isr Med Assoc J 2020;22:22-6.

91. Rusthoven CG, Yamamoto M, Bernhardt D, et al. Evaluation of First-line Radiosurgery vs WholeBrain Radiotherapy for Small Cell Lung Cancer Brain Metastases: The FIRE-SCLC Cohort Study. JAMA Oncol 2020;6:1028-37.

92. Yamamoto M, Serizawa T, Shuto T, et al. Stereotactic radiosurgery for patients with multiple brain metastases (JLGK0901): a multi-institutional prospective observational study. Lancet Oncol 2014;15:387-95.

93. Viani GA, Gouveia AG, Louie AV, et al. Stereotactic radiosurgery for brain metastases from small cell lung cancer without prior whole-brain radiotherapy: A metaanalysis. Radiother Oncol 2021;162:45-51.

94. Sperduto PW, Kased N, Roberge D, et al. Summary report on the graded prognostic assessment: an accurate and facile diagnosis-specific tool to estimate survival for patients with brain metastases. J Clin Oncol 2012;30:419-25.

95. Harris S, Chan MD, Lovato JF, et al. Gamma knife stereotactic radiosurgery as salvage therapy after failure of whole-brain radiotherapy in patients with small-cell lung cancer. Int J Radiat Oncol Biol Phys 2012;83:e53-9.

96. Steindl A, Schlieter F, Klikovits T, et al. Prognostic assessment in patients with newly diagnosed small cell lung cancer brain metastases: results from a real-life cohort. J Neurooncol 2019;145:85-95.

97. Berghoff AS, Wolpert F, Holland-Letz T, et al. Combining standard clinical blood values for improving survival prediction in patients with newly diagnosed brain metastases-development and validation of the LabBM score. Neuro Oncol 2017;19:1255-62. 